Vol.60: e17160339, January-December 2017 http://dx.doi.org/10.1590/1678-4324-2017160339 ISSN 1678-4324 Online Edition
BRAZILIAN ARCHIVES OF BIOLOGY AND TECHNOLOGY

AN INTERNATIONAL JOURNAL

\title{
Production and Optimization of Killer Toxin in Debaryomyces hansenii Strains
}

\author{
Cengiz Çorbacı $^{1,2 *}$, Füsun Bahriye Uçar ${ }^{2}$ \\ ${ }^{I}$ Giresun University - Faculty of Engineering, Department of Genetic and Bioengineering, Giresun, Turkey; \\ ${ }^{2}$ Ege University - Faculty of Science, Biology Department, Basic and Industrial Microbiology Section, Izmir, \\ Turkey.
}

\begin{abstract}
Postharvest diseases of fruits and vegetables result in critical losses of production in worldwide. The losses often are caused by fungi and nowadays, most fungal pathogens are controlled by several strategies such as the use of fungicides. However, most of the fungicides are chemical-based compounds and are dangerous to human health and the nature. Therefore, the discovery of healthy and reliable strategies is crucial to control of fungal pathogens. In the paper, it was aimed to evaluate and characterize yeast isolates previously isolated from dairy products for the production of killer toxin. A total of 18 yeasts have been found to produce antagonistic behavior against susceptible fungal species. All of the yeasts expressing killer character were characterized by using several molecular techniques, and isolates TEM8 and 17 identified as D. hansenii have showed the strongest antifungal activities. Improvement of killer toxin production by the yeasts also has been studied, and the highest production was found in YMB medium containing $\mathrm{NaCl}(6 \%)$ and DMSO (1000 ppm) at pH 4.0 and $20^{\circ} \mathrm{C}$. The killer characters of these yeasts have indicated the potential use of the yeasts as antagonists for the control of postharvest diseases in agricultural industries.
\end{abstract}

Key words: characterization, killer toxin, optimization, postharvest disease, yeast

\footnotetext{
*Author for correspondence: cengizcorbaci@windowslive.com
} 


\section{INTRODUCTION}

Fungi are one of the major factors encountered in postharvest diseases of numerous vegetables and fruits and are considered to be a cause of high economic losses in all over the world ${ }^{1-3}$. Nowadays, synthetic fungicides are used generally in postharvest applications and are the most important agents for reducing fungal-based losses. Nevertheless, the use of synthetic compounds has been progressively restrained because of consumers' no longer want to see toxic or chemical residues in their foods ${ }^{3}$. Furthermore, the increasing occurrence of phytopathogens that are resistant to chemical agents encourages the necessitate to seek for different alternatives for disease control $^{4-6}$.

It is well known that members of certain groups of microorganisms have the ability to produce and secrete extracellular compounds that display antagonistic behaviors against others ${ }^{7}$. Biological control using antagonists seems to be a particularly promising approach to protect different fruits and vegetables from fungal infections ${ }^{3,8}$. Biological agents help reduce the use of chemical-based compounds and this is one of the most important reasons to consider their use. In most cases, due to their low or no toxicity to higher organisms they are safer to use. Moreover, they are more stable and less phytotoxic than chemical agents ${ }^{3,9,10}$.

Recently, numerous researchers have reported the use of mechanisms of yeast antagonism for the control of fungal-based postharvest losses ${ }^{11-13}$. Probably the most significant antagonistic behavior by yeasts is the production of killer proteins (toxins) firstly discovered in Saccharomyces cerevisiae by Makower and Bevan ${ }^{14}$. These proteins are known to be active against organisms taxonomically related to their producers ${ }^{10}$. These toxins target the components of the fungal cell walls, and as mammalian cells lack the components, the agents do not damage the host cells. Killer character has been detected in above 90 yeast species ${ }^{15}$.

Most of the killer yeasts have many characteristics, and these features make them efficient bio-agents in the preservation of fruits and vegetables. These yeasts have simple nutritional requirements, and are therefore easily produced in large-scales. Also, they do not harbor pathogenic or toxic potentials, in contrast to filamentous fungi ${ }^{3,9}$. Hence, in the present paper, we aimed to evaluate and characterize yeasts expressing killer phenotype as potential biocontrol agents for fungal diseases.

\section{MATERIALS AND METHODS}

\section{Fungal strains and cultivation conditions}

Yeast strains were provided from a previous research related to Turkish style homemade dairy products ${ }^{16}$. The yeast and mold strains were maintained at $4{ }^{\circ} \mathrm{C}$ respectively on Yeast Malt (YM) agar [g/L, yeast extract, 3; malt extract, 3; peptone, 5; glucose, 10; and agar, 15] and Potato Dextrose Agar (PDA) [g/L, potatoes, 200; dextrose, 20; and agar, 20]. Fungi used as susceptible-test organisms for killer proteins are listed Table 1.

Table 1 - Fungi used as susceptible-test organisms

\begin{tabular}{ll}
\hline Aspergillus niger NRRL 326 & Kluyveromyces lactis NRRL Y-8279 \\
Candida albicans NRRL Y-7875 & Kluyveromyces marxianus NRRL Y-1109 \\
Candida rugosa NRRL Y-95 & Saccharomyces cerevisiae NRRL Y-12632 \\
Candida tropicalis NRLL YB-366 & Wickerhamomyces anomalus NRRL Y-366 \\
Candida zeylanoides NRRL Y-1774 & Yarrowia lipolytica CBS 6124 \\
Debaryomyces hansenii NRRL Y-7426 &
\end{tabular}




\title{
Screening of killer phenotype
}

Killer phenotype was determined in triplicate on Killer Medium $(\mathrm{KM})$ agar $[\mathrm{g} / \mathrm{L}$, yeast extract, 3; malt extract, 3; peptone, 5; glucose, 10; agar, 15; and methylene blue, 0.03; buffered at $\mathrm{pH} 4.0$ with $100 \mathrm{mM} \mathrm{Na} \mathrm{HPO}_{4}$-citrate buffer]. Media pHs were checked before and after autoclaving and the differences were never exceeded 0.1-0.2 units.

Screening for yeasts against several fungi was conducted according to the method by Hashem and Alamri ${ }^{13}$ with minor modifications. The overnight yeast cultures and four-day-old mycelium of Aspergillus niger NRRL 326 were suspended in sterile distilled water $(\mathrm{dw})$ and appropriate amounts taken from the cell suspensions were inoculated into $\mathrm{KM}$ agar (kept at $45^{\circ} \mathrm{C}$ ) to get $2 \times 10^{6}$ cells $/ \mathrm{ml}$ after pouring. After the plates incubated at $20^{\circ} \mathrm{C}$ for $72 \mathrm{~h}$, isolates were considered killer protein producers if they formed an inhibition zone against the susceptible organisms.

\section{DNA sequencing and restriction fragment length polymorphism (RFLP) analysis of ribosomal RNA regions}

Genomic DNAs were isolated according to Liu et $\mathrm{al}^{17}$. The amplification reactions of ribosomal RNA regions and oligonucleotide primers used were given in a previous paper $^{18}$.

The sequences from D1/D2 domain of 26S rRNA regions produced using primers NL1 and NL4 were matched using a BLASTN search and aligned with the sequences in GenBank database using CLUSTAL W2.0 software.

For RFLP analyses, PCR amplicons of ITS1-5.8SrRNA-ITS2 and 18S rRNA regions obtained with the primer pairs ITS1 - ITS4 and P108 - M3976, respectively, were used. Amplification products were digested separately by fast digest restriction endonucleases (Fermentas) HaeIII, HinfI, Sau3AI, Sau96I and TaqI, and reaction mixtures were incubated according to the manufacturer's instruction. To predict and verify the size of each restriction fragment, Nebcutter V2.0 programme, available at http://tools.neb.com/NEBcutter2, was used.

\section{Production and improvement of killer toxin}

The most efficient killer toxin producing yeasts were grown in 1 liter Erlenmeyer flasks with $500 \mathrm{ml}$ of Yeast malt broth (YM) medium buffered with $100 \mathrm{mM}$ $\mathrm{Na}_{2} \mathrm{HPO}_{4}$-citric acid ( $\mathrm{pH} 4.0$ ). The optical densities of the cultures were adjusted at $600 \mathrm{~nm}$ in a spectrophotometer. Aliquots of $50 \mathrm{ml}$ were transferred in sterile falcon tubes to determine the toxin production.

Table 2 - The components of culture media used in the improvement of the killer toxin production

Media
Yeast carbon base broth (YCB)
Yeast extract peptone glucose broth (YEPD)
Yeast nitrogen base broth (YNB)
Yeast malt broth (YMB)
Potato dextrose broth (PDB)

\author{
Components (g/L) \\ Bacto yeast carbon base, 11.7; peptone, 5 \\ Yeast extract, 10; peptone, 20; glucose, 20 \\ Bacto yeast nitrogen base, 6.7 ; glucose, 5 \\ Yeast extract, 3; malt extract, 3; peptone, 5; glucose, 10 \\ Potato infusion, 4 ; glucose, 20
}

The overnight yeast cultures were grown in $250 \mathrm{ml}$ Erlenmeyer flasks containing 50 $\mathrm{ml}$ of buffered media. To improve killer toxin production, different media [Yeast carbon base broth (YCB), Yeast extract peptone glucose broth (YEPD), Yeast nitrogen base broth (YNB), Yeast malt broth (YMB) and Potato dextrose broth (PDB)] were investigated as a first step for the toxin production. The components of the media used are listed Table 2. All media buffered with $100 \mathrm{mM} \mathrm{Na} \mathrm{HPO}_{4}$-citric acid $(\mathrm{pH} 4.0)$ were incubated at $20^{\circ} \mathrm{C}$ in a rotary bed shaker at $150 \mathrm{rpm}$. Having selected the best producing medium, the medium was then supplemented with 
different additives [Ammonium sulfate, Dimethyl sulfoxide (DMSO), Glycerol, Phenylmethylsulfonyl fluoride (PMSF), Sodium dodecyl sulfate (SDS), Sorbitol, Triton-X 100 and Tween 80] using two concentrations (100 and $1000 \mathrm{ppm}$ ), different $\mathrm{NaCl}$ concentrations $(0-10 \%, \mathrm{w} / \mathrm{v})$ and evaluated with different growth temperatures (10 to $30^{\circ} \mathrm{C}$ ) and $\mathrm{pHs}$ (3.0 to 6.0). The killer activities of the samples were determined and compared with the preliminary production rates.

\section{Determination of protein content and killer toxin assay}

Protein concentrations of the samples were estimated according to the Bradford method using bovine serum albumin as standard ${ }^{19}$.

Killer toxin assay was performed using paper discs $(6 \mathrm{~mm})$ on $\mathrm{KM}$ agar inoculated with Candida tropicalis NRLL YB-366 strain. The supernatants obtained from $50 \mathrm{ml}$ culture samples centrifuged at $5000 \mathrm{rpm}$ and $4^{\circ} \mathrm{C}$ for $10 \mathrm{~min}$ were filtered using a $0.45 \mu \mathrm{m}$ syringe membranes and the protein contents in the supernatants were precipitated with ice-cold ethanol to a final concentration of $70 \%(\mathrm{v} / \mathrm{v})$. The pellets were recovered by centrifugation at $7000 \mathrm{rpm}$ and $4{ }^{\circ} \mathrm{C}$ for $10 \mathrm{~min}$ and resuspended in $100 \mathrm{mM} \mathrm{Na} \mathrm{HPO}_{4}$-citric acid ( $\mathrm{pH} 4.0$ ) buffer ${ }^{20}$. The killer activity was measured as the diameter of the inhibition zone, and the activity was expressed in arbitrary units (AU). Under the conditions studied, a linear relationship was observed between the diameter of the inhibition zone and the logarithm of the protein concentration in the solution tested. The toxin resulting in an inhibition zone with a $1 \mathrm{~mm}$ diameter is defined as $1 \mathrm{AU}$.

\section{RESULTS AND DISCUSSION}

To control the targets and reduce the usage of different inappropriate environmental methods, prioritizing the use of agents isolated from their intrinsic environments reveals a giant potential during postharvest points ${ }^{5,8}$. Isolating novel strains harboring antifungal properties from different habitats is of great importance for postharvest disease control ${ }^{4,6}$. Some yeasts exhibit antagonistic behaviors toward other microorganisms such as yeasts and molds by producing killer toxins. This phenomenon is quite important and it has potential for the use of postharvest practices.

In present paper, it was aimed to evaluate and characterize yeasts expressing killer character, and all of the isolates investigated were obtained from domestic sources (cheese and yoghurt). These isolates and susceptible-test organisms were maintained at $4^{\circ} \mathrm{C}$ on appropriate media and killer toxin producing isolates were determined on $\mathrm{KM}$ agar supplemented with methylene blue at $20^{\circ} \mathrm{C}$ for $72 \mathrm{~h}$. From the initial yeast collection, 18 isolates $(32 \%)$ produced an inhibition zone against at least one susceptible strain and were classified as killer yeasts (Table 3). The blue zone of cellular death was not considered to be an evident and these yeast isolates were regarded as antagonists. As seen in Table 3, two isolates (named as TEM8 and 17) have showed strong antifungal activity to most (9 of 11) of the tested organisms, followed by TEM31 ( 7 of 11) and TEM9 and 21 (6 of 11), respectively. The efficacy of killer character seems to different from strain to strain among the targets compatible with previous reports ${ }^{21,22}$. For this reason, it is very important to investigate the potential use of yeast strains isolated from different sources for the control of fungal pathogens. Killer yeasts are often isolated from foods and can inhibit growth of other fungal pathogens. Bleve et al. ${ }^{23}$ tested yeasts to select isolates showing a killer phenotype against Aspergillus carbonarius and A. niger, and authors identified 28 isolates exhibiting the antagonistic behaviors from an initial group of 144 yeast isolates. The results from inhibition experiments indicated that 
Killer toxin production from Debaryomyces hansenii

some of the yeasts significantly reduced the colonization of the pathogenic fungi on wounded berries.

Table 3 - Antagonistic activities of yeast isolates against susceptible-fungal species

\begin{tabular}{|c|c|c|c|c|c|c|c|c|c|c|c|}
\hline \multirow{3}{*}{ Strain No. } & \multicolumn{11}{|c|}{ Inhibition Zones (Diameter of inhibition zone - Diameter of organism, mm) } \\
\hline & \multicolumn{11}{|c|}{$\begin{array}{ll}\text { Susceptible Fungi } \\
\end{array}$} \\
\hline & A. $n$ & C. $a$ & C.r & C.t & C. $z$ & D.h & K.l & K.m & S.c & W.a & Y.l \\
\hline TEM1 & $w$ & $w$ & - & - & - & 9 & $w$ & $w$ & - & 3 & - \\
\hline TEM5 & 3 & $w$ & - & - & 8 & 5 & $w$ & - & - & $w$ & $w$ \\
\hline TEM6 & - & $w$ & 3 & 3 & - & $w$ & $w$ & - & 6 & 9 & 15 \\
\hline TEM7 & - & $w$ & 3 & 2 & - & $w$ & - & - & 8 & 9 & 16 \\
\hline TEM8 & 8 & 3 & 12 & 11 & - & $w$ & 11 & 3 & 11 & 7 & 21 \\
\hline TEM9 & 2 & $w$ & 5 & 5 & - & $w$ & $w$ & - & 6 & 9 & 18 \\
\hline TEM10 & $w$ & $w$ & 3 & 3 & - & $w$ & - & - & 6 & 8 & 15 \\
\hline TEM14 & - & $w$ & 5 & 6 & - & $w$ & $w$ & - & 7 & 9 & 15 \\
\hline TEM15 & $w$ & $w$ & 5 & 6 & - & $w$ & $w$ & - & 5 & 9 & 16 \\
\hline TEM17 & 7 & 3 & 12 & 11 & - & - & 8 & 4 & 5 & 11 & 20 \\
\hline TEM18 & 4 & $w$ & - & - & - & $w$ & $w$ & - & 4 & - & 6 \\
\hline TEM21 & $w$ & 5 & 6 & 7 & - & $w$ & $w$ & - & 6 & 9 & 16 \\
\hline TEM22 & 5 & $w$ & - & - & - & $w$ & $w$ & - & 4 & $w$ & $w$ \\
\hline TEM29 & 4 & $w$ & - & - & - & $w$ & 5 & $w$ & - & 3 & - \\
\hline TEM31 & $w$ & 8 & 2 & 2 & 10 & - & - & - & 5 & 14 & 19 \\
\hline TEM35 & 2 & $w$ & - & - & - & - & 7 & - & 5 & $w$ & $w$ \\
\hline TEM52 & 2 & 6 & - & - & - & 6 & 7 & - & 5 & - & $w$ \\
\hline TEM60 & 4 & $w$ & - & - & 5 & 5 & $w$ & - & 5 & $w$ & $w$ \\
\hline
\end{tabular}

A.n, A. niger NRRL 326; C.a, C. albicans NRRL Y-7875; C.r, C. rugosa NRRL Y-95; C.t, C. tropicalis NRLL YB366; C.z, C. zeylanoides NRRL Y-1774; D.h, D. hansenii NRRL Y-7426; K.l, K. lactis NRRL Y-8279; K.m, K. marxianus NRRL Y-1109; S.c, S. cerevisiae NRRL Y-12632; W.a, W. anomalus NRRL Y-366; Y.l, Y. lipolytica CBS 6124; $w$, weak

In the present paper, killer toxin producing isolates were characterized by using sequencing of D1/D2 domain of 26S rRNA gene and RFLP analysis of ITS15.8SrRNA-ITS2 and 18S rRNA gene regions. According to the BLAST results of D1/D2 domain, 10 of 18 isolates including the most efficient killer yeasts TEM8 and 17 were successfully identified as Debaryomyces hansenii, and the others were Candida zeylanoides, Meyerozyma guilliermondii and Pichia kudriavzevii (Table 4). PCR amplification of ITS1-5.8SrRNA-ITS2 gene region produced amplicon sizes in 530 and $640 \mathrm{bp}$ (Table 4). Digestion of these fragments by restriction endonucleases (HaeIII, HinfI, Sau3AI and Sau96I) revealed that isolates belonging to the closely related species represented similar RFLP profiles at least for these endonucleases. In other words, RFLP analysis did not differentiate the yeasts from each other accurately. Only the isolate TEM5 identified as $P$. kudriavzevii by sequencing showed completely different RFLP patterns for the all tested endonucleases. In addition to these results, RFLP analysis led to possible false readings and experimental mistakes as such in isolates TEM5 and 8. In cases of TEM5 and 8, RFLP patterns obtained from the isolates were not matched to that of any yeast species and type species used. Therefore, ITS-RFLP analysis was performed again for these isolates, and it was found that the previous results were incorrect. Ultimately, the finally obtained RFLP patterns were compatible with that of belonging to the species and type species by sequencing.

PCR amplification of 18S rRNA gene region rendered amplicon size in $1800 \mathrm{bp}$, and such in the other gene region, RFLP patterns of this region produced similar results for the closely related species (Table 4). Besides, two isolates TEM1 and 5 identified respectively as $C$. zeylanoides and $P$. kudriavzevii by sequencing showed partly different RFLP patterns for the all tested endonucleases. 
Table 4 - Molecular characterization of yeasts expressing killer character

\begin{tabular}{|c|c|c|c|c|c|c|c|c|c|c|c|c|}
\hline \multirow{3}{*}{$\begin{array}{l}\text { Strain } \\
\text { No. }\end{array}$} & \multicolumn{5}{|c|}{ ITS1-5.8S rDNA-ITS2 } & \multicolumn{4}{|c|}{ 18S rDNA } & \multicolumn{3}{|c|}{ D1/D2 domain of 26S rDNA } \\
\hline & \multirow{2}{*}{$\begin{array}{c}\text { PCR } \\
(\mathbf{b p})\end{array}$} & \multicolumn{4}{|c|}{ Restriction Fragments (bp) } & \multirow{2}{*}{$\begin{array}{c}\text { PCR } \\
(\mathbf{b p})\end{array}$} & \multicolumn{3}{|c|}{ Restriction Fragments (bp) } & \multirow{2}{*}{$\begin{array}{l}\text { PCR } \\
\text { (bp) }\end{array}$} & \multirow{2}{*}{$\underset{(\%)}{\text { Homology }}$} & \multirow{2}{*}{$\begin{array}{c}\text { Identification Result } \\
\text { (GenBank Accession } \\
\text { Number) }\end{array}$} \\
\hline & & HaeIII & HinfI & Sau3AI & Sau96I & & HaeIII & HinfI & TaqI & & & \\
\hline TEM1 & 640 & $420+140+80$ & $320+320$ & $400+220$ & $500+140$ & 1800 & $510+290+270+180+160+150+120+80$ & $830+600+240+110$ & $410+400+380+240+210$ & 549 & 99 & $\begin{array}{c}\text { Candida zeylanoides } \\
\text { (JQ277230) }\end{array}$ \\
\hline TEM5 & 530 & $380+90$ & $220+150+140$ & $370+130$ & 530 & 1800 & $500+230+210+180+160+150+120+70$ & $800+540+230+130$ & $590+500+290+240$ & 559 & 99 & $\begin{array}{l}\text { Pichia kudriavzevii } \\
\text { (JQ277231) }\end{array}$ \\
\hline TEM6 & 640 & $420+140+80$ & $320+320$ & $400+220$ & $500+140$ & 1800 & $500+270+180+170+160+150+120+110+80$ & $810+600+240+110$ & $410+400+390+260+200+80$ & 571 & 99 & $\begin{array}{c}\text { Debaryomyces hansenii } \\
\text { (JQ277232) }\end{array}$ \\
\hline TEM7 & 640 & $420+140+80$ & $320+320$ & $400+220$ & $500+140$ & 1800 & $500+270+180+170+160+150+120+110+80$ & $810+600+240+110$ & $410+400+390+260+200+80$ & 572 & 99 & $\begin{array}{l}\text { Debaryomyces hansenii } \\
\text { (JQ277233) }\end{array}$ \\
\hline TEM8 & 640 & $420+140+80$ & $320+320$ & $400+220$ & $500+140$ & 1800 & $500+270+180+170+160+150+120+110+80$ & $810+600+240+110$ & $410+400+390+260+200+80$ & 570 & 98 & $\begin{array}{l}\text { Debaryomyces hansenii } \\
\text { (JQ277234) }\end{array}$ \\
\hline TEM9 & 640 & $420+140+80$ & $320+320$ & $400+220$ & $500+140$ & 1800 & $500+270+180+170+160+150+120+110+80$ & $810+600+240+110$ & $410+400+390+260+200+80$ & 561 & 99 & $\begin{array}{l}\text { Debaryomyces hansenii } \\
\text { (JQ277235) }\end{array}$ \\
\hline TEM10 & 640 & $420+140+80$ & $320+320$ & $400+220$ & $500+140$ & 1800 & $500+270+180+170+160+150+120+110+80$ & $810+600+240+110$ & $410+400+390+260+200+80$ & 557 & 99 & $\begin{array}{l}\text { Debaryomyces hansenii } \\
\text { (JQ277236) }\end{array}$ \\
\hline TEM14 & 640 & $420+140+80$ & $320+320$ & $400+220$ & $500+140$ & 1800 & $500+270+180+170+160+150+120+110+80$ & $810+600+240+110$ & $410+400+390+260+200+80$ & 559 & 99 & $\begin{array}{l}\text { Debaryomyces hansenii } \\
\text { (JQ277237) }\end{array}$ \\
\hline TEM15 & 640 & $420+140+80$ & $320+320$ & $400+220$ & $500+140$ & 1800 & $500+270+180+170+160+150+120+110+80$ & $810+600+240+110$ & $410+400+390+260+200+80$ & 561 & 99 & $\begin{array}{l}\text { Debaryomyces hansenii } \\
\text { (JQ277238) }\end{array}$ \\
\hline TEM17 & 640 & $420+140+80$ & $320+320$ & $400+220$ & $500+140$ & 1800 & $500+270+180+170+160+150+120+110+80$ & $810+600+240+110$ & $410+400+390+260+200+80$ & 563 & 99 & $\begin{array}{l}\text { Debaryomyces hansenii } \\
\text { (JQ277239) }\end{array}$ \\
\hline TEM18 & 640 & $390+140+80$ & $320+320$ & $400+220$ & $400+140+80$ & 1800 & $500+270+180+170+160+150+120+110+80$ & $810+600+240+110$ & $410+400+390+260+200+80$ & 542 & 99 & $\begin{array}{l}\text { Meyerozyma guilliermondii } \\
\text { (JQ277240) }\end{array}$ \\
\hline TEM21 & 640 & $420+140+80$ & $320+320$ & $400+220$ & $500+140$ & 1800 & $500+270+180+170+160+150+120+110+80$ & $810+600+240+110$ & $410+400+390+260+200+80$ & 565 & 99 & $\begin{array}{c}\text { Debaryomyces hansenii } \\
\text { (JQ277241) }\end{array}$ \\
\hline TEM22 & 640 & $390+140+80$ & $320+320$ & $400+220$ & $400+140+80$ & 1800 & $500+270+180+170+160+150+120+110+80$ & $810+600+240+110$ & $410+400+390+260+200+80$ & 549 & 99 & $\begin{array}{l}\text { Meyerozyma guilliermondii } \\
\text { (JQ277242) }\end{array}$ \\
\hline TEM29 & 640 & $390+140+80$ & $320+320$ & $400+220$ & $400+140+80$ & 1800 & $500+270+180+170+160+150+120+110+80$ & $810+600+240+110$ & $410+400+390+260+200+80$ & 539 & 99 & $\begin{array}{c}\text { Meyerozyma guilliermondii } \\
\text { (JQ277243) }\end{array}$ \\
\hline TEM31 & 640 & $420+140+80$ & $320+320$ & $400+220$ & $500+140$ & 1800 & $500+270+180+170+160+150+120+110+80$ & $810+600+240+110$ & $410+400+390+260+200+80$ & 560 & 98 & $\begin{array}{l}\text { Debaryomyces hansenii } \\
\text { (JQ277244) }\end{array}$ \\
\hline TEM35 & 640 & $390+140+80$ & $320+320$ & $400+220$ & $400+140+80$ & 1800 & $500+270+180+170+160+150+120+110+80$ & $810+600+240+110$ & $410+400+390+260+200+80$ & 565 & 99 & $\begin{array}{l}\text { Meyerozyma guilliermondii } \\
\text { (JQ277245) }\end{array}$ \\
\hline TEM52 & 640 & $390+140+80$ & $320+320$ & $400+220$ & $400+140+80$ & 1800 & $500+270+180+170+160+150+120+110+80$ & $810+600+240+110$ & $410+400+390+260+200+80$ & 566 & 99 & $\begin{array}{l}\text { Meyerozyma guilliermondii } \\
\text { (JQ277246) }\end{array}$ \\
\hline TEM60 & 640 & $390+140+80$ & $320+320$ & $400+220$ & $400+140+80$ & 1800 & $500+270+180+170+160+150+120+110+80$ & $810+600+240+110$ & $410+400+390+260+200+80$ & 567 & 99 & $\begin{array}{l}\text { Meyerozyma guilliermondii } \\
\text { (JQ277247) }\end{array}$ \\
\hline C.z & 640 & $420+140+80$ & $320+320$ & $400+220$ & $500+140$ & 1800 & $510+290+270+180+160+150+120+80$ & $830+600+240+110$ & $410+400+380+240+210$ & & & \\
\hline D.h & 640 & $420+140+80$ & $320+320$ & $400+220$ & $500+140$ & 1800 & $500+270+180+170+160+150+120+110+80$ & $810+600+240+110$ & $410+400+390+260+200+80$ & & & \\
\hline M.g & 640 & $390+140+80$ & $320+320$ & $400+220$ & $400+140+80$ & 1800 & $500+270+180+170+160+150+120+110+80$ & $810+600+240+110$ & $410+400+390+260+200+80$ & & & \\
\hline$P . k$ & 530 & $380+90$ & $220+150+140$ & $370+130$ & 530 & 1800 & $500+230+210+180+160+150+120+70$ & $800+540+230+130$ & $590+500+290+240$ & & & \\
\hline
\end{tabular}

C.z, C. zeylanoides NRRL Y-1774; D.h, D. hansenii NRRL Y-7426; M.g, M. guilliermondii ATCC 6260; P.k, P. kudriavzevii ATCC 24210 
In the last decades, several identification techniques have been recommended as alternatives instead of time-consuming classical methods. However, as in conventional methods, there are several reports presenting a single molecular technique lead to misidentification of an organism in some cases. For instance, Arias et al. $^{24}$ compared several approaches for characterization, and in terms of accurate identification, partial sequencing of the 26S rRNA was found to yield the best results, followed by classical techniques and ITS analysis. On the other hand, in several studies, it was stated that D1/D2 domain of 26S rRNA region could not differentiate closely related taxa. In a study performed by Daniel and Meyer ${ }^{25}$, several gene sequences were investigated for the effectiveness of species differentiation. As a result of their experiments, researchers concluded that D1/D2 domain of 26S rRNA region is not specific for closely related taxa and recommended the use of more than one gene region for identification purposes. In our study, considering the aforementioned cases and Table 4, it was seen that the use of one gene region or method did not provide the accurate identification of the closely related species. Above mentioned possible false readings and experimental mistakes, and lack of full database for each enzyme can cause false identification, and this situation reduces the reliability of RFLP analysis. This study has demonstrated once again that using of a combination consisting of several different methods is a crucial stage for the accurate identification of an organism.

In most studies, it is indicated that the culture conditions influence the production of killer toxin and the optimal conditions should be found empirically ${ }^{20,26}$. Therefore, in the present paper, the production of killer toxins by D. hansenii TEM8 and 17 in different media was compared (Fig. 1). Although all media supported the growth of the killer yeasts, the production of killer toxin in YNB medium was not observed. Accumulation of the killer toxins in extracellular medium at $\mathrm{pH} 4,20^{\circ} \mathrm{C}$ and $150 \mathrm{rpm}$ was empirically found to be high in YM medium. Also, the medium yielded killer toxin with a high specific activity than the other media used, followed by YCB, YEPD and PDB medium, respectively. Because of YM medium is a more minimized medium and provide higher specific activity than the others, the medium was chosen for the further studies.

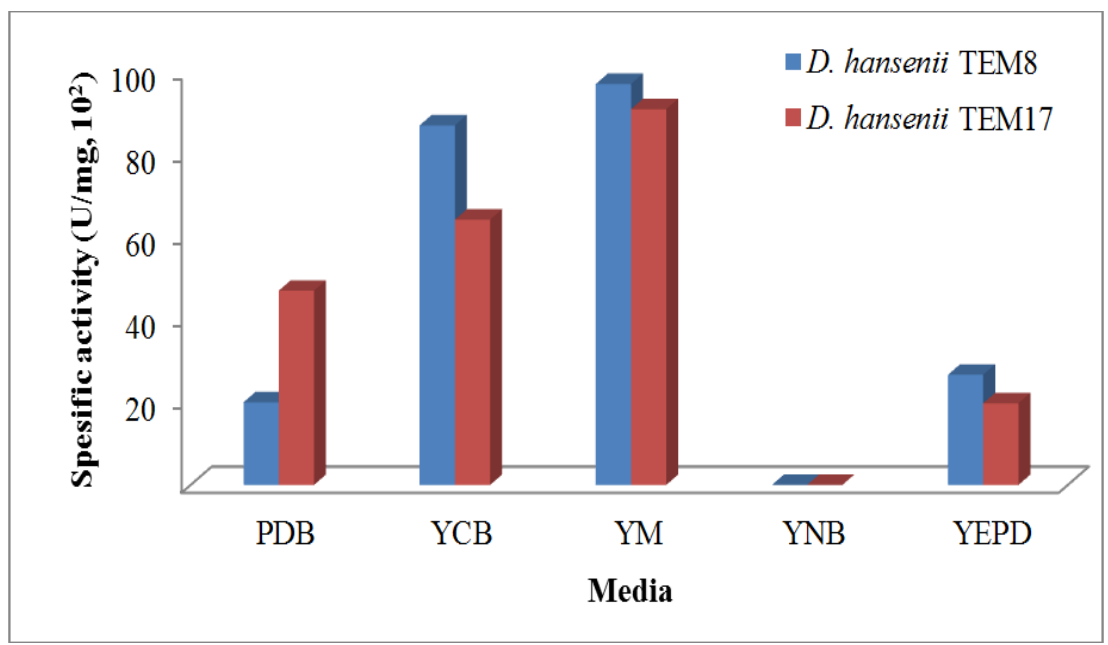

Figure 1 - Media used in killer toxin production at $\mathrm{pH} 4.0$ and $20^{\circ} \mathrm{C}$

To improve the production of killer toxin, YM medium was supplied with different agents and evaluated at varied growth temperatures and pHs. Marquina et al. ${ }^{20}$ reported that the optimal temperature of toxin production by $D$. hansenii strain used was at $20^{\circ} \mathrm{C}$ and occurred between 5 and $35^{\circ} \mathrm{C}$. Researchers also indicated that above 
pH 5.0 irreversibly inactivate most toxins and killer toxins are active particularly in a narrow $\mathrm{pH}$ range. In our experiments, different temperatures $\left(10\right.$ to $\left.30^{\circ} \mathrm{C}, \mathrm{Fig} .2\right)$ and pHs (3.0 to 6.0, Fig. 3) have supported the killer toxin production by $D$. hansenii strains in different amounts. The toxin production reached the highest levels at $\mathrm{pH}$ 4.0 and $20^{\circ} \mathrm{C}$. These findings were compatible with the literatures ${ }^{20,26}$. However, interestingly, the toxin production has still continued above $\mathrm{pH} 5.0$, and it stopped completely at $\mathrm{pH}$ 6.5. These findings indicated that our strains have the ability to produce the killer toxins in a wide range of temperature and $\mathrm{pH}$.

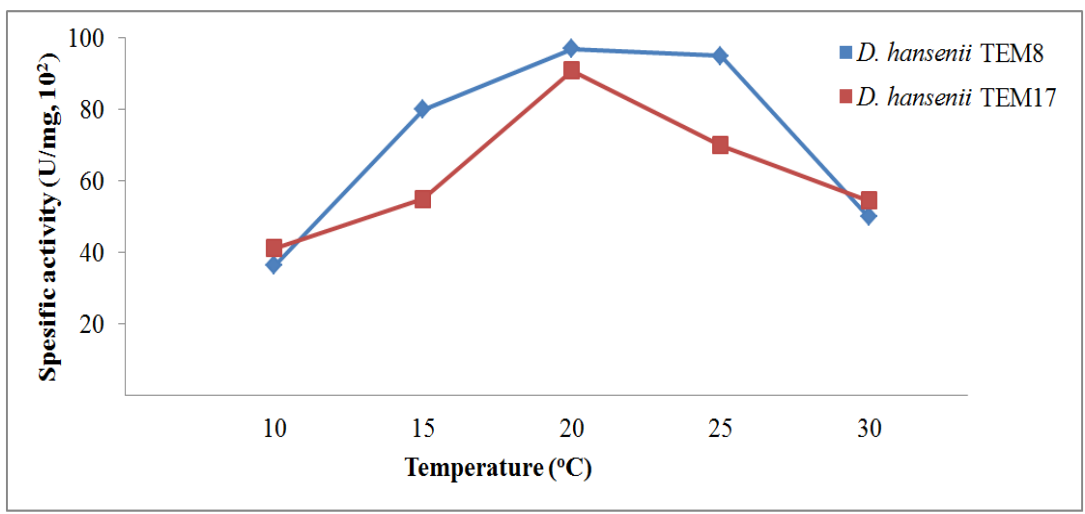

Figure 2 - Effect of temperature on killer toxin production at $\mathrm{pH} 4.0$

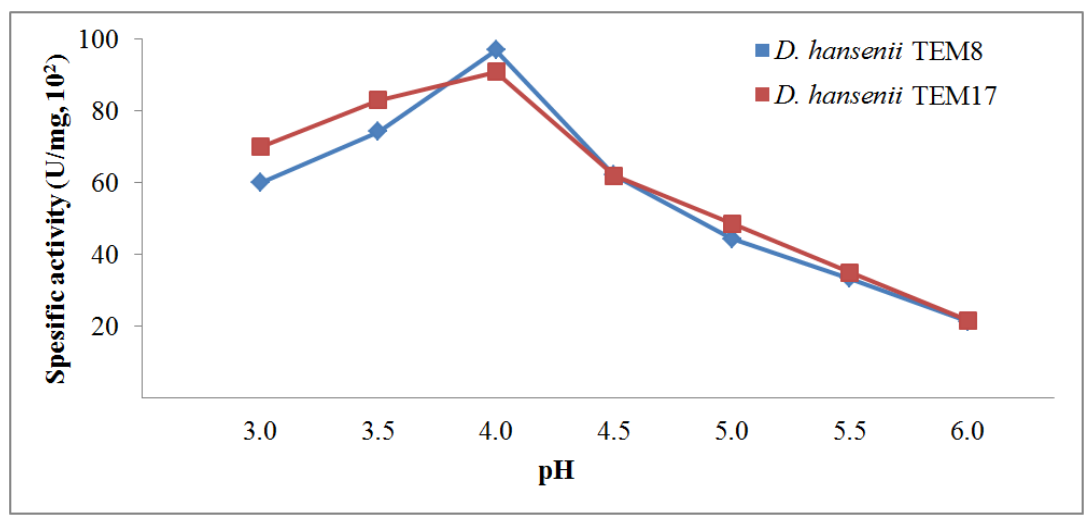

Figure 3 - Effect of $\mathrm{pH}$ on killer toxin production at $20^{\circ} \mathrm{C}$

The addition of reagents, including organic solvents, polyhydric alcohols, protease inhibitors, salts and non-ionic and ionic detergents, is known to stabilize some unstable proteins by preventing inactivation in solutions ${ }^{27,28}$. Marquina et al ${ }^{20}$ found the most efficient additive to be DMSO $(100 \mathrm{ppm})$ on the toxin production by $D$. hansenii strain investigated. Besides, researchers reported that PEGs also were effective, although sorbitol, glycerol and PMSF did not improve the production. In our killer strains, D. hansenii TEM8 and 17, DMSO also increased the toxin production considerably at the concentration of $1000 \mathrm{ppm}$, and the addition of other additives did not improve the production at the concentration analyzed (Fig. 4). On the other hand, ammonium sulfate and non-ionic detergents significantly reduced the killer toxin production, and ionic detergent SDS inhibited the growth and toxin production completely compatible with previous observations ${ }^{20,26}$. 


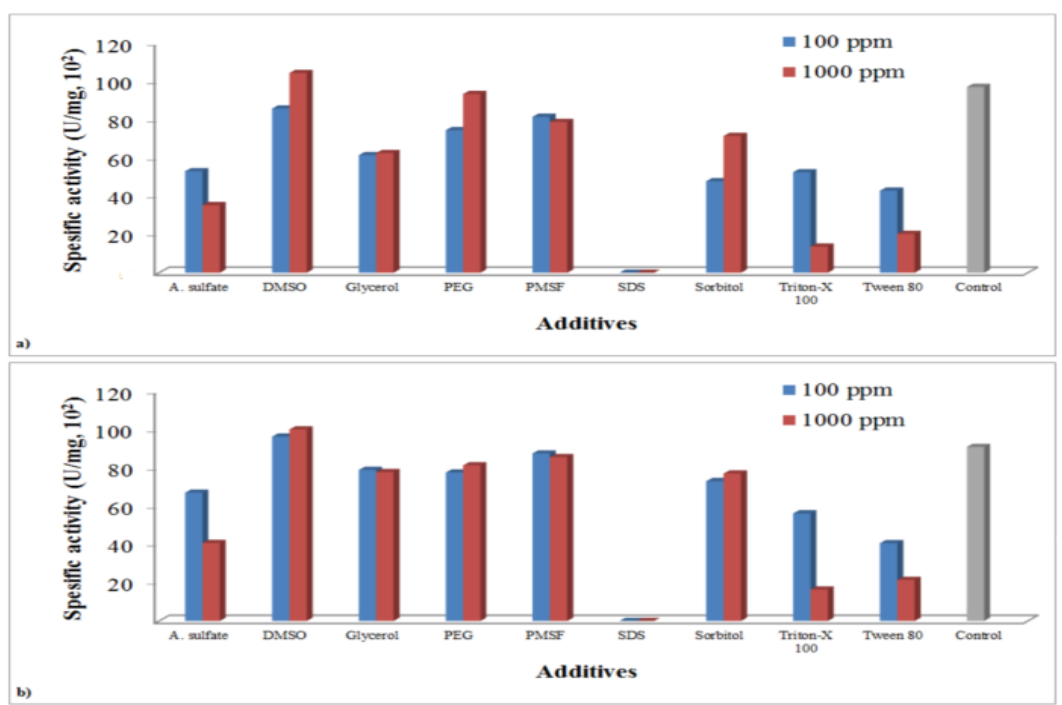

Figure 4 - Effect of different additives on killer toxin production at $\mathrm{pH} 4.0$ and $20^{\circ} \mathrm{C}$; a) $D$. hansenii TEM8, b) D. hansenii TEM17

Because of $D$. hansenii strains are known to grow better in media containing sodium chloride, we also investigated the effect of $\mathrm{NaCl}$ concentrations on the production of killer toxin (Fig. 5). The toxin production was found to be best at a concentration of $\mathrm{NaCl}$ at $6 \%(\mathrm{w} / \mathrm{v})$. Above and below this concentration, the production decreased gradually and these results were also compatible with previous findings ${ }^{20,26}$.

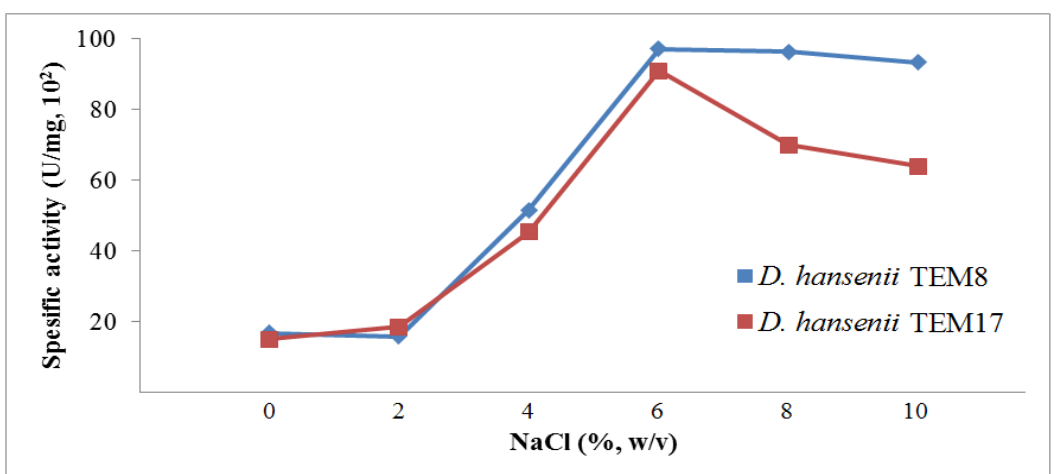

Figure 5 - Effect of $\mathrm{NaCl}$ concentration on killer toxin production at $\mathrm{pH} 4.0$ and $20^{\circ} \mathrm{C}$

The use of bio-agents to control postharvest diseases of fruits and vegetables has been investigated as an alternative to the use of synthetic fungicides and a few commercial products are available nowadays. Discovery of novel microorganisms having antagonistic behaviors is important task because antagonistic microorganisms lived in domestic sources may be more effective against the pathogenic fungi present in that $\operatorname{areas}^{2}$

The characteristic properties of the genus Debaryomyces that endows it with such a potential has recently been reviewed by Breuer and Harms ${ }^{29}$. It is a yeast with numerous application areas in biotechnological processes such as dairy and meat fermentations, synthesis of fine chemicals and production of proteolytic and lypolytic enzymes. Besides, the antagonistic activity of $D$. hansenii of dairy and nondairy origins is relatively well known. Payne and Bruce ${ }^{30}$ investigated its activity on fungal spoilage of sawn Pinus sylvestris timber and reported that this yeast considerably reduced disfiguration of autoclaved sapwood blocks inoculated with mixtures of common wood-inhabiting molds or blue-stain fungi. Also, Hernández- 
Montiel et al. ${ }^{31}$ studied the biocontrol performances of $D$. hansenii strains isolated from marine environments and they suggested it can be used for biocontrol of postharvest diseases caused by Penicillium italicum on Mexican lime. On the other hand, several researchers evaluated killer character of $D$. hansenii strains isolated from dairy products and they also suggested it as an efficient biological agent to inhibit growth of several pathogenic yeast and moulds ${ }^{22,32}$.

The outcomes defined in this paper revealed that D. hansenii strain TEM8 and 17, isolated from cheeses, had also great potentials to manage diseases caused by fungi. The toxin production in these strains was improved in YM medium, and the addition of DMSO contributes to the maximum levels of toxin production. No doubt, more studies are needed before the incorporation of these strains in biotechnological applications. Therefore, additional studies are planned to elucidate the structures and in vivo biocontrol efficiencies of killer proteins produced from these strains.

\section{REFERENCES}

1-Filtenborg O, Frisvad JC, Traen U. Moulds in food spoilage. Int J Food Microbiol. 1996; 33: 85-102.

2-Gholamnejad J, Etebarian HR, Sahebani N. Biological control of apple blue mold with Candida membranifaciens and Rhodotorula mucilaginosa. Afr J Food Sci. 2010; 4(1): 1-7.

3-de Lima JR, Gonçalves LRB, Brandão LR, Rosa CA, Viana FMP. Isolation, identification, and activity in vitro of killer yeasts against Colletotrichum gloeosporioides isolated from tropical fruits. J Basic Microbiol. 2012; 53: 590-599.

4-Lima G, De Curtis F, Piedimonte D, Spina AM, De Cicco V. Integration of biological control yeast and thiabendazole protects stored apples from fungicide sensitive and resistant isolates of Botrytis cinerea. Postharvest Biol Technol. 2006; 40: 301-307.

5-Droby S, Wisniewski M, Macarisin D, Wilson C. Twenty years of postharvest biocontrol research: is it time for a newparadigm?. Postharvest Biol Technol. 2009; 52: 137-145.

6-Lima G, Castoria R, De Curtis F, Raiola A, Ritieni A, De Cicco V. Integrated control of blue mould using new fungicides and biocontrol yeasts lowers levels of fungicide residues and patulin contamination in apples. Postharvest Biol Technol. 2011; 60: 164-172.

7-Viljoen BC. Yeast ecological interactions. Yeast-yeast, yeast-bacteria, yeast-fungi interactions and yeasts as biocontrol agents. In Querol A and Fleet GH, editors. Yeasts in Food and Beverages. Springer-Verlag, Berlin; 2006. p. 83-110.

8-Janisiewicz WJ, Korsten L. Biological control of postharvest diseases of fruits. Annu Rev Phytopathol. 2002; 40: 411-441.

9-Spadaro D, Gullino ML. State of the art and future prospects of the biological control of postharvest fruit diseases. Int J Food Microbiol. 2004; 91: 185-194.

10- Golubev WI. Antagonistic interactions among yeasts. In Rosa CA and Peter G, editors. The Yeast Handbook: Biodiversity and Ecophysiology of Yeasts. Springer, Berlin; 2006. p. 197-219.

11-Dal Bello G, Monaco C, Rollan MC, Lampugnani G, Arteta N, Abramoff C, et al. Biocontrol of postharvest grey mould on tomato by yeasts. J Phytopathol. 2008; 156: 257 263.

12- Kefialewa Y, Ayalewb A. Postharvest biological control of anthracnose (Colletotrichum gloeosporioides) on mango (Mangifera indica). Postharvest Biol Technol. 2008; 50: 8-10.

13- Hashem M, Alamri S. The biocontrol of postharvest disease (Botryodiplodia theobromae) of guava (Psidium guajava L.) by the application of yeast strains. Postharvest Biol Technol. 2009; 53: 123-130.

14- Makover M, Bevan EA. The inheritance of a killer character in yeast Saccharomyces cerevisiae. Proceedings of the XI International Congress of Genetics; 1963. 1: 202.

15- Buzzini P, Turchetti B, Vaughan-Martini AE. The use of killer sensitivity patterns for biotyping yeast strains: the state of the art, potentialities and limitations. FEMS Yeast Res. 2007; 7: 749-760. 
16- Corbaci C, Ucar FB, Yalcin HT. Isolation and characterization of yeasts associated with Turkish-style homemade dairy products and their potential as starter cultures. Afr $J$ Microbiol Res. 2012; 6: 534-542.

17- Liu D, Coloe S, Baird R, Pederson J. Rapid mini-preparation of fungal DNA for PCR. $J$ Clin Microbiol. 2000; 38(1): 471.

18- Yalçın HT, Çorbacı C, Uçar FB. Molecular characterization and lipase profiling of the yeasts isolated from environments contaminated with petroleum. J Basic Microbiol. 2013; 54(1): 85-92.

19- Bradford MA. A rapid and sensitive method for the quantitation of microgram quantities of protein utilizing the principle of protein-dye binding. Anal Biochem. 1976; 31: 426-428.

20- Marquina D, Barroso J, Santos A, Peinado JM. Production and characteristics of Debaryomyces hansenii killer toxin. Microbiol Res. 2001; 156: 387-391.

21-Buzzini P, Martini A. Utilisation of differential killer toxin sensitivity patterns for fingerprinting and clustering yeast strains belonging to different genera. Syst Appl Microbiol. 2000; 23: 450-457.

22- Banjara N, Nickerson KW, Suhr M.J, Hallen-Adams HE. Killer toxin from several foodderived Debaryomyces hansenii strains effective against pathogenic Candida yeasts. Int J Food Microbiol. 2016; 222: 23-29.

23- Bleve G, Grieco F, Cozzi G, Logrieco A, Visconti A. Isolation of epiphytic yeasts with potential for biocontrol of Aspergillus carbonarius and A. niger on grape. Int J Food Microbiol. 2006; 108: 204-209.

24- Arias CR, Burns JK, Friedrich LM, Goodrich RM, Parish ME. Yeast species associated with orange juice: evaluation of different identification methods. Appl Environ Microbiol. 2002; 68(4): 1955-1961.

25- Daniel HM, Meyer W. Evaluation of ribosomal RNA and actin gene sequences for the identification of ascomycetous yeasts. Int J Food Microbiol. 2003; 86: 61-78.

26- Santos A, Marquina D. Killer toxin of Pichia membranifaciens and its possible use as a biocontrol agent against grey mould disease of grapevine. Microbiol. 2004; 150: 25272534.

27- Ouchi K, Kawase N, Nakano S, Akiyama H. Stabilization of yeast killer factor by glycerol. Agric Biol Chem. 1978; 42: 1-5.

28- Ohta Y, Tsukada Y, Sugimori T. Production, purification and characterization of HYI, an antiyeast substance, produced by Hansenula saturnus. Agric Biol Chem. 1984; 48: 903-908.

29-Breuer U, Harms H. Debaryomyces hansenii - an extremophilic yeast with biotechnological potential. Yeast. 2006; 23: 415-437.

30- Payne C, Bruce A. The yeast Debaryomyces hansenii as a short-term biological control agent against fungal spoilage of sawn Pinus sylvestris timber. Biol Control. 2001; 22: 2228.

31- Hernández-Montiel LG, Ochoa JL, Troyo-Diéguez E, Larralde-Corona CP. Biocontrol of postharvest blue mold (Penicillium italicum Wehmer) on Mexican lime by marine and citrus Debaryomyces hansenii isolates. Postharvest Biol Technol. 2010; 56(2): 181-187.

32- Liu SQ, Tsao M. Biocontrol of dairy moulds by antagonistic dairy yeast Debaryomyces hansenii in yoghurt and cheese at elevated temperatures. Food Control. 2009; 20: 852-855. 